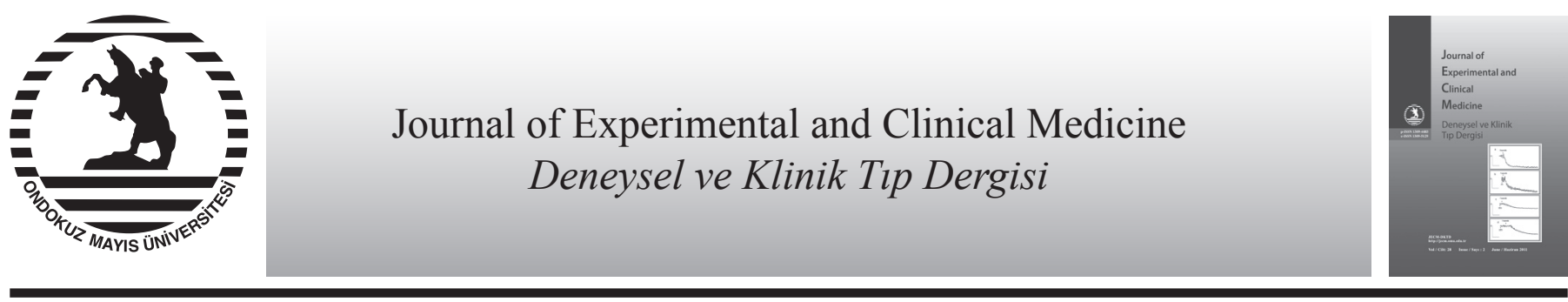

Olgu Sunumu / Case Report

\title{
Çocuklarda kistik abdominal lenfanjiomalar: iki olgu sunumu
}

\author{
Cystic abdominal lymphangioma in children: report of two cases
}

\author{
Erdal Türk ${ }^{\mathrm{a}}$, Naile Dölek ${ }^{\mathrm{b}}$, Hakan Duman ${ }^{\mathrm{c}}$, Yılmaz Baş ${ }^{\mathrm{d}}$ \\ ${ }^{a}$ Ordu Kadın Doğum ve Çocuk Hastalıkları Hastanesi, Çocuk Cerrahisi Kliniği, Ordu \\ ${ }^{b}$ Ordu Kadın Doğum ve Çocuk Hastalıkları Hastanesi, Ordu \\ ${ }^{c}$ Ordu Kadın Doğum ve Çocuk Hastalıkları Hastanesi, Patoloji Kliniği, Ordu \\ ${ }^{d}$ Çorum Devlet Hastanesi, Patoloji Kliniği, Çorum
}

\begin{tabular}{|c|c|}
\hline MAK & GÍLERİ \\
\hline Ma & \\
\hline Geliş & $23 / 12 / 2009$ \\
\hline Kabul & $01 / 04 / 2010$ \\
\hline
\end{tabular}

* Yazışma Adresi:

Erdal Türk

Erenler Mah, 211. Sokak

No:4/4, 20045

Yenişehir/Denizli

e-posta : eturk19@yahoo.de

\section{Anahtar Kelimeler:}

Karında kitle

Mezenterik kistik

Lenfanjioma

Ultrasonografi

Bilgisayarlı tomografi

Çocukluk çağı

Cerrahi tedavi

\section{Keywords:}

Abdominal mass

Mesenteric cystic

Lymphangioma

Ultrasound

Computed tomography

Childhood

Surgical treatment

\section{ÖZET}

Abdominal kistik lenfanjiomlar, literatürde sık rastlanmayan, mezenterik ve retroperitoneal lenfatiklerin iyi huylu doğumsal anomalileridir. Klinik sunumlar değişkendir ve çoğu zaman semptom vermezler. Tanı genellikle, fizik muayene, ultrasonografi ve bilgisayarlı tomografi ile konmaktadır. Eğer komşu organların önemli bir kısmı feda edilmeyecekse, kitlenin cerrahi olarak tamamen çıkartılması, semptomatik abdominal kistik lenfanjiomaların tedavi edici seçeneğidir. Bu çalışmada, cerrahi tedavi uygulanan iki mezenterik kistik lenfanjiomalı hasta sunulmuştur. Aralıklı karın ağrısı ve karında kitle nedeniyle müracaat eden 3 yaşında erkek ve 2,5 yaşında kız hastalarda yapılan radyolojik incelemeler sonucu karın içerisinde komşu organlara bası yapan düzgün sınırlı, septalı mezenterik kistik lenfanjiom saptandı. Her iki hastaya da cerrahi tedavi uygulanarak kitle eksizyonu uygulanırken ikinci hastaya barsak rezeksiyonu da uygulandi. Her iki hastada da ameliyat sonrası sorun oluşmadı ve şifa ile taburcu edildiler. Mezenterik kistik lenfanjiomlar çocuklarda nadir görülen patolojilerdir. Aralıklı karın ağrısı ve karında kitle şikayeti olan hastalarda akılda tutulmalı, nadirde olsa ciddi komplikasyonlara neden olabileceğinden seçilmiş vakalarda cerrahi tedavi uygulanmalıdır.

J. Exp. Clin. Med., 2011; 28:79-82

\begin{abstract}
Abdominal cystic lymphangiomas are benign congenital abnormalities of the mesenteric and retroperitoneal lymphatics that are not commonly reported. The clinical presentation is variable and generally asymptomatic. The diagnosis is usually made with the physical examination, ultrasonography and computed tomography. The treatment of choice for symptomatic abdominal cystic lymphangiomas is complete surgical excision of the mass if a large portion of adjacent organs will not have to be sacrificed. We present two mesenteric cystic lymphangioma cases that underwent surgical treatment in this study. A 3-year-old male and 2.5-year-old female who presented with intermittent abdominal pain and an abdominal mass underwent radiological investigation and smooth-bordered, septate mesenteric cystic lymphangiomas were found within the abdomen. Surgical treatment was used for both patients with one undergoing mass excision by itself and the second patient with intestinal resection. There were no postoperative problems in either patient and both were discharged with full recovery. Mesenteric cystic lymphangiomas are common pathologies in children. They should be kept in mind in patients with intermittent abdominal pain and an abdominal mass, and surgical treatment should be used in selected cases as they can cause serious complications although rarely.

J. Exp. Clin. Med., 2011; 28:79-82
\end{abstract}

(C) 2011 OMU All rights reserved

\section{Giriş}

Kistik lenfanjiomlar, lenfatik sistem tıkanıklığına bağlı olarak, içi sıvı dolu kistlerin oluştuğu, lenf damarlarının iyi huylu bir proliferasyonudur (Muramori ve ark., 2009). Çocuk- larda sıklıkla baş, boyun ve koltuk altında ortaya çıkarlar. İntraperitoneal ve retroperitoneal kistik lenfanjiomlar doğumsal kaynaklı, oldukça nadir görülen iyi huylu tümörlerdir (Prabhakaran ve ark., 2007). Hastaların yaklaşık olarak \%60'ına 
beş yaşından önce tanı konur ve erkeklerde kızlardan daha sık görülür (Weeda ve ark., 2008). Çoğu asemptomatik olmasına rağmen, kistin boyut ve lokalizasyonuna bağlı olarak, bazen abdominal distansiyon, karın ağrısı, intestinal obstruksiyon, volvulus, kist içine kanama, kistin rüptürüne bağlı akut batın gibi yaşamı tehdit edici komplikasyonlara yol açma potansiyelleri de vardır (Kovalivker ve ark., 1987; Chung ve ark., 1991; Ulman ve ark., 1995). Bu çalışmada aralıklı karın ağrısı ve karın şişliği nedeniyle müracaat eden ve yapılan incelemelerinde mezenterik kistik lenfanjiom saptanan iki hasta sunulmuştur.

\section{Olgular}

Olgu 1: Üç yaşında erkek hasta 1 yıldır aralıklı süren ve son 1 aydır belirginleşen karın ağrısı ve karında şişlik şikâyetiyle müracaat etti. Fizik muayenede karın sağ üst ve alt kadranını tamamen dolduran, hareketli, yumuşak kıvamda ve düzgün sınırlı kitle dışında bir özellik yoktu. Rutin laboratuar incelemelerinde hemoglobin: $9 \mathrm{mg} / \mathrm{dl}$ ve hemotokrit: \%27 idi. Yapılan karın ultrasonografisinde batın orta hattan sağ yana doğru uzanım gösteren ve hareketle yer değiştiren $20 \times 15 \mathrm{~cm}$ uzunluğunda septalı kistik hiperekoik kistler saptandı. Çekilen kontrastlı karın tomografisinde pankreas komşuluğundan başlayıp karın sağ yanına uzanan ve barsakları sola doğru iterek pelvise kadar uzanım gösteren, komşu organlarla bağlantısı olmayan yaklaşık $21 \times 16 \times 10 \mathrm{~cm}$ uzunluğunda kistik yer kaplayıcı oluşum saptandı (Şek. 1).

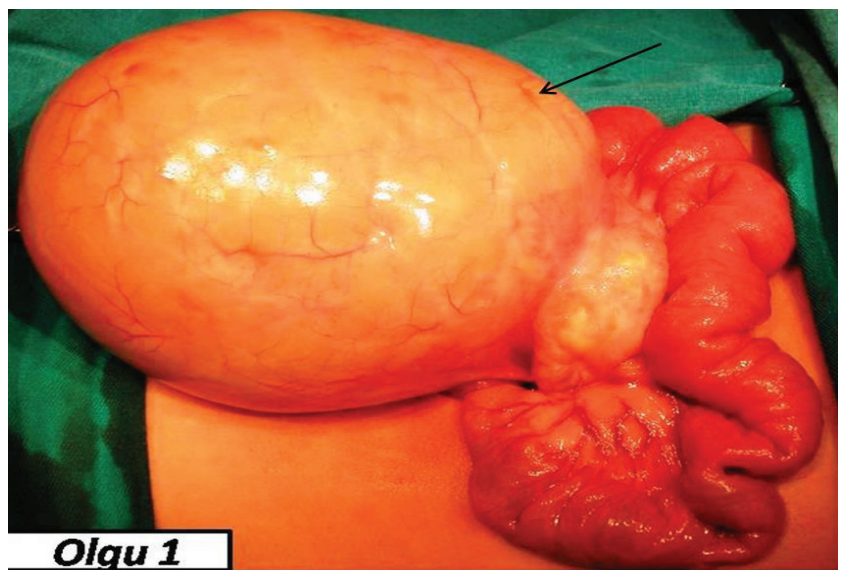

Şek. 1a: Olgu 1'e ait kistlerin ameliyat sırasındaki görüntüsü.

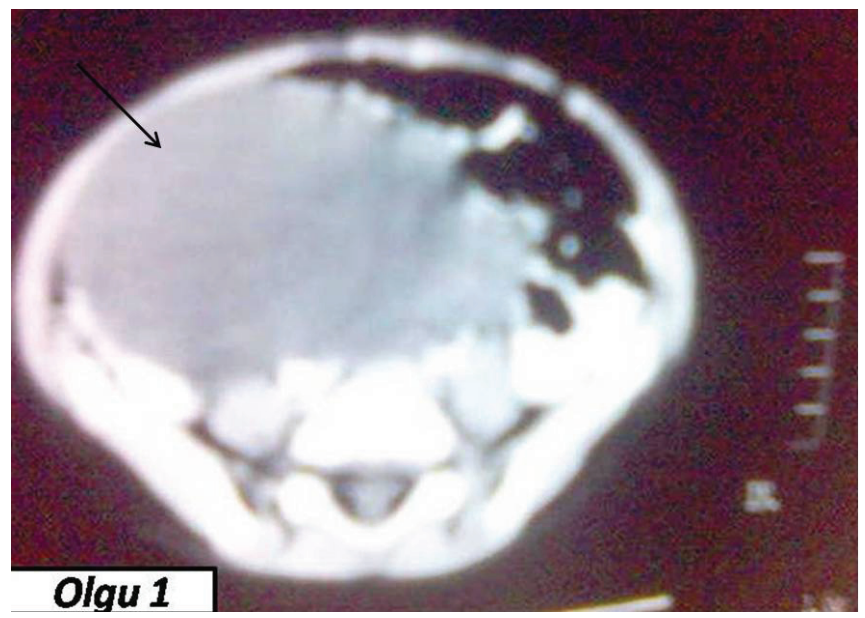

Şek.1b: Olgu 1'e ait kontrastlı tomografi kesitlerinde kistlerin görüntüsü.
Kitlenin büyük olması ve hastada karın ağrısına neden olması nedeniyle hasta operasyona alındı. Operasyonda ince barsak mezosundan köken alan ve en büyüğü yaklaşık olarak 20x15 cm olan çok sayıda kistik kitle saptandı (Şek. 1a). Barsak dolaşımı bozulmayacak şekilde en büyük kitle (Şek. 1b) ile beraber çok sayıda küçük kitle total olarak eksize edildi. Oluşan mezo defekti primer olarak onarıldı. Ameliyat sonrası 2. gününde beslenmeye başlanan hasta 4 . gününde taburcu edildi. Kitlenin patolojik incelenmesi kistik lenfanjiom olarak değerlendirildi. Yapılan 3. ay ve 1. yil kontrol muayenesinde ve ultrasonografisinde herhangi bir patoloji saptanmadı.

Olgu 2: İki buçuk yaşında kız hasta, son 15 gündür karın ağrısı ve aralıklı kusma şikayetleriyle gittiği çocuk hastalıkları uzmanı tarafından değerlendirilmiş. Yapılan karın ultrasonografisinde karın içinde kistik kitle saptanması üzerine polikliniğimize sevk edilmiş. Hastanın fizik muayenesinde karın orta ve sağ alt kadranında hareketli, düzgün sınırlı ve yumuşak kıvamda kitle saptandı. Laboratuar değerlendirmelerinde herhangi bir patoloji saptanmayan hastanın çekilen intravenöz ve oral kontrastlı batın tomografisinde batın orta hattından başlayıp sağa doğru uzanım gösteren, aşağıda mesane ile komşuluk gösteren lobule konturlu, gergin ve distansiyon oluş̧urmayan, anatomik boşluğa göre şekil alan, yaklaşık $13 \times 5 \times 8 \mathrm{~cm}$ ebatlarında kistik kitle saptand. Kistin çevresinde boyanma izlenmemekteydi. (Şek. 2a). Hastada semptomlara neden olması ve kitlenin büyük olması nedeniyle operasyona karar verildi. Operasyonda Treitz ligamanının yaklaşık $30 \mathrm{~cm}$ distalinde, jejunumu eyer şeklinde saran 10x12 cm ve 8x10 $\mathrm{cm}$ büyüklüğünde 2 adet ve çok sayıda kü̧̈ük kistik yapı ile karşılaşıldı (Şek. 2b).

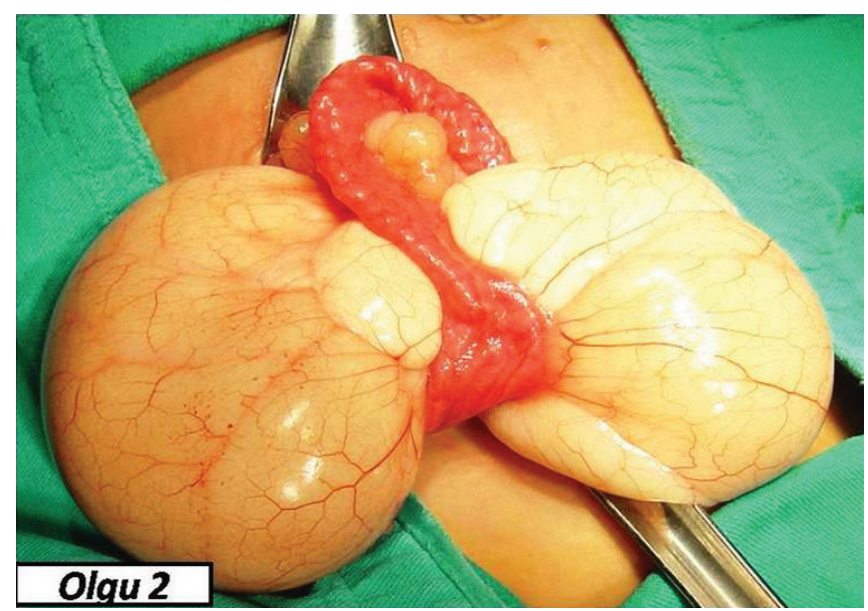

Şek. 2a: Olgu 2'ye ait kistlerin ameliyat sırasındaki görüntüsü.

Kitlelerin tam olarak çıartılması mümkün olmadığı için yaklaşı $10 \mathrm{~cm}$ 'lik jejunum ansı ile birlikte rezeke edildi. Barsak bütünlüğü yapılan jejuno-jejunostomi ile sağlandı. Postoperatif dönemde sorunu olmayan hasta 3 . gün beslenmeye başlandı ve 5. gün taburcu edildi. Kitlenin histopatolojik değerlendirilmesi şilöz kistik lenfangiom olarak değerlendirildi. Ameliyat sonrası 3. ay fizik muayenesi ve batın ultrasonografisi normal olan hasta halen takip edilmekte. 


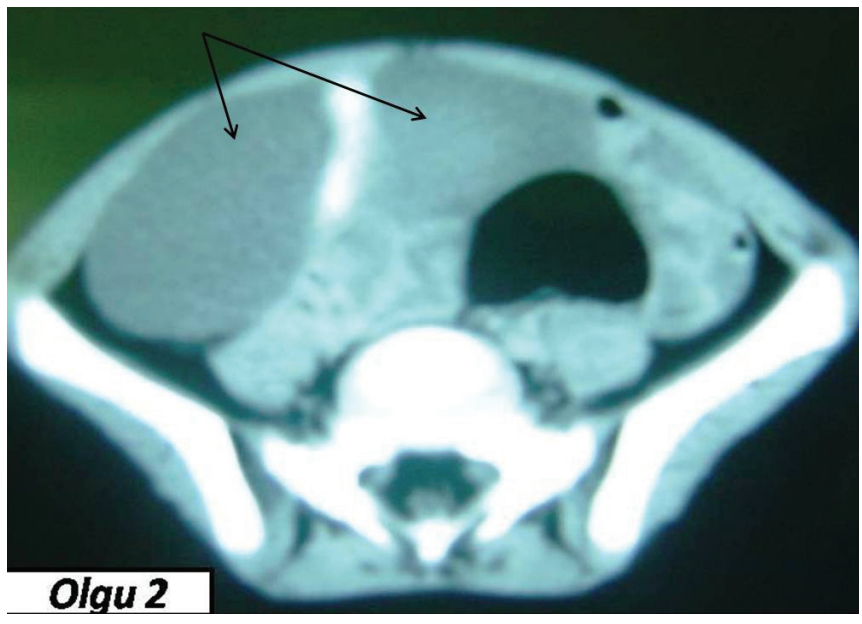

Şek. 2b: Olgu 2'ye ait kontrastlı tomografi kesitlerinde kistlerin görüntüsü (iki büyük kistin arasında oral kontrast madde ile boyanmış parlak renkte ince barsak segmenti görünmekte)

\section{Tartışma}

Mezenterik kistik lenfangiomalar (MKL) son derece nadir görülen benign kistik lezyonlardır. Çocuk hastanelerine müracaat eden 20.000 hastadan birinde görülür (Prabhakaran ve ark., 2007). Genellikle asemptomatik olmalarına rağmen, akut olarak volvulus ve intestinal infarktüsa bağlı olarak oluşan barsak tıkanıklığı ile müracaat edebilirler. Hastaların \%58'ininin muayenesinde ise ağrısız, yumuşak ve hareketli bir kitle ele gelebilir (Gunel ve ark., 1996; Weeda ve ark., 2008). Karın şişliği, karın ağrısı, bulantı, safralı kusma, ishal ve kabızlık görülebilecek diğer semptomlardır (Kosir ve ark., 1991; Egozi ve ark., 1997). Bizim her iki hastamızda karın ağrısı şikâyetiyle doktora başvuran ve fizik muayenede karında hareketli kitle saptanan hastalard1.

Mezenterik kistik lenfangiomalar'ın tanısında genellikle ultrasonografi yeterli olmasına rağmen karın tomografiside kullanılmaktadır. Kistik teratom, müsinöz kistadenom, bronkojenik kist, over kistleri, nonpankreatik pseudokist ve komplike asit gibi diğer asemptomatik karın içi kitleler ile karışma potansiyelleri mevcuttur (Muramori ve ark., 2009). Ancak kesin tanı patolojik inceleme sonucu konur (İlce ve ark., 2006). Biz hastalarımızın tanısında öncelikle ultrasonografi, daha sonra hem oral hem de intravenöz kontrast vererek çektiğimiz karın tomografisini kullandık. Bu şekilde yer kaplayıcı oluşumun boyut, lokalizasyon ve yapısal özellikle- rine ek olarak komşu organlar ile olan ilişkisini de daha net değerlendirdik.

Mezenter kistleri, iç yüzeyleri tek sıralı endotel ile döşeli fibröz duvarları olan, şilöz veya seröz sıvı içeren uniloküler veya multiloküler kistlerdir (Mollitt ve ark., 1978; Kovalivker ve ark., 1987). İnce barsak mezosu veya mezokoloun herhangi bir yerinden kaynaklanabildiği gibi \%50 olguda kistlerin özellikle ileumdan kaynaklandığı saptanmıştır (Mollitt ve ark., 1978; Gunel ve ark., 1996). Seröz sıvı içeren kistlerin mezokolondan, şilöz sıvı içeren kistlerin ise ince barsak mezenterinden kaynaklandığı bildirilmektedir (Ulman ve ark., 1995; Gunel ve ark., 1996). Her iki olgumuzda da kitleler ince barsak mezosundan köken almaktaydı ve içerdikleri sıvı şilöz nitelikteydi. İkinci olgunun yerleşim alanı biraz daha proksimalde, duvarı daha ince, sıvı miktarı daha fazlaydı.

Mezenter kistlerinin tedavisinde genellikle küçük ve klinik bulgu vermeyen kistlerin klinik muayene ve ultrasonografi ile takibi önerilmektedir (Konen ve ark., 2002). Son zamanlarda baş boyun bölgesi başta olmak üzere karın içi lenfanjiomlarda dahil OK-432, Bleomisin ve İnterferon gibi kimyasal ajanların kullanımıyla da başarılı sonuçlar bildirilmiştir (Konen ve ark., 2002; Rha ve ark., 2003; Muir ve ark., 2004; Sichel ve ark., 2004). Kitlenin laparoskopik olarak çıkartılması ile ilgili özellikle erişkinlerde başarılı sonuçlar bildirilmiştir (Varadarajulu ve ark., 2008). Ancak çocuklarda tercih edilen asıl tedavi yöntemi, özellikle büyük kistlerin söz konusu olduğu durumlarda kistin mezosu ile beraber ilişkide olduğu barsak parçası ile beraber çıkartılıp rezeksiyon anastomoz uygulanmasıdır. Aksi taktirde kitlenin tekrarlaması söz konusu olabilir (Gunel ve ark., 1996; Konen ve ark., 2002; İlce ve ark., 2006). Bizim her iki olgumuzda da kist boyutları büyük olduğu için laparotomi tercih edilmiştir. Birinci olgumuzda kistin ve mezenterinin çıkartılması sonucu barsak dolaşımı etkilenmediği için bu barsak bölümünün çıkartılmasına da gerek kalmamıştır. Ancak ikinci olguda barsak dolaşımı bozulduğu için yaklaşık $10 \mathrm{~cm}$ 'lik bir alana rezeksiyon anastomoz uygulandi.

Sonuç olarak MKL, semptom ve bulguları çok çeşitlilik gösteren ve çocuklarda çok nadir görülen batın içi kistik kitlelerdir. Aralıklı karın ağrısı şikayeti ile müracaat eden çocuklarda, dikkatli bir fizik muayene, ultrasonografi ve kontrastlı batın tomografisi ile tanısı konmaktadır. Kitlenin büyük boyutlara ulaştığı durumlarda, nadir de olsa ciddi komplikasyonlara neden olabileceği için cerrahi rezeksiyon uygulanmalidir.

\section{KAYNAKLAR}

Chung, M.A., Brandt, M.L., St-Vil, D., Yazbeck, S., 1991. Mesenteric cysts in children. J. Pediatr. Surg. 26, 1306-1308.

Egozi, E.I., Ricketts, R.R., 1997. Mesenteric and omental cysts in children. Am. Surg. 63, 287-290.

Gunel, E., Cağlayan, F., Gundogan, A., 1996. Nadir Görülen Karında Kitle Nedeni: Mezenter Kisti. T. Klin. Pediatri 5, 74-76.

İlce, Z., Erdogmus, B., Aslener, A., Yazıc1, B., 2006. Çocuklarda Nadir Görülen Jejunal Mezenterik Kistik Lenfanjiom. Turk. Klin. J. Pediatr. $15,80-82$.

Konen, O., Rathaus, V., Dlugy, E., Freud, E., Kessler, A., Shapiro, M., Horev, G., 2002. Childhood abdominal cystic lymphangioma. Pediatr. Radiol. 32, 88-94.

Kosir, M.A., Sonnino, R.E., Gauderer, M.W., 1991. Pediatric abdominal lymphangiomas: a plea for early recognition. J. Pediatr. Surg. 26, 13091313.

Kovalivker, M., Motovic, A., 1987. Obstruction and gangrene of bowel with perforation due toa mesenteric cyst in a newborn. J. Pediatr. Surg. 22, 377-378.

Mollitt, D.L., Ballantine, T.V., Grosfeld, J.L., 1978. Mesenteric cysts in infancy and childhood. Surg. Gynecol. Obstet. 147, $182-184$.

Muir, T., Kirsten, M., Fourie, P., Dippenaar, N., Ionescu, G.O., 2004. Intralesional bleomycin injection (IBI) treatment for haemangiomas and congenital vascular malformations. Pediatr. Surg. Int. 19, 766-773.

Muramori, K., Zaizen, Y., Noguchi, S., 2009. Abdominal lymphangioma in children: report of three cases. Surg. Today 39, $414-417$. 
Prabhakaran K, Patankar J Z, Loh DLSK, Ahamed Faiz Ali M A, 2007. Cystic lymphangioma of the mesentery causing intestinal obstruction. Singapore Med. J. 48, e265-e267.

Rha, S.E., Byun, J.Y., Kim, H.H., Shin, J.C., Ahn, H.Y., Kim, D.C., Lee, K.Y., 2003. Prenatal sonographic and MR imaging findings of extensive fetal lymphangioma: a case report. Korean J. Radiol. 4, 260-263.

Sichel, J.Y., Udassin, R., Gozal, D., Koplewitz, B.Z., Dano, I., Eliashar, R., 2004. OK-432 therapy for cervical lymphangioma. Laryngoscope. $114,1805-1809$.

Ulman, I., Herek, O., Ozok, G., Avanoglu, A., Erdener, A., 1995. Traumatic rupture of mesenteric cyst: a life-threatening complication of a rare lesion. Eur. J. Pediatr. Surg.5, 238-239.

Varadarajulu, S., Arnoletti, J.P., 2008. Laparoscopic assistance for endoscopic resection of early stage esophageal cancer (with video). Gastrointest. Endosc. 68, 181-183.

Weeda, V.B., Booij, K.A., Aronson, D.C., 2008. Mesenteric cystic lymphangioma: a congenital and an acquired anomaly? Two cases and a review of the literature. J. Pediatr. Surg. 43, 1206-1208. 